\title{
SOBRE ALGUMAS TENTATIVAS DE SUPERAÇÃO DO DOGMATISMO: O MARXISMO TCHECO NOS ANOS 1960
}

\author{
Pedro Leão da Costa Neto ${ }^{1}$
}

\begin{abstract}
Resumo: O processo de desestalinização, desencadeado com a morte de Stalin e a sucessiva leitura do relatório Khrushchov frente ao XX Congresso do PCUS, veio acompanhado de intensos debates teóricos que levaram a um verdadeiro florescimento do pensamento marxista na Europa Oriental. Na Tchecoslováquia, igualmente, estes debates foram de grande relevância e deram origem a um verdadeiro pluralismo no interior da teoria marxista. As obras de Jindřich Zelený, Karel Kosik e Robert Kalivoda representaram três diferentes tentativas de diálogo com a tradição filosófica, com a obra de Marx e o marxismo, assim como, com diferentes tendências teórico-filosóficas existentes na Tchecoslováquia e expressaram três diferentes respostas a crise do dogmatismo oficial.
\end{abstract}

Palavras Chaves: Marxismo Tcheco, Jindřich Zelený, Karel Kosik e Robert Kalivoda

\begin{abstract}
The process of de-Stalinization, triggered by Stalin's death and the subsequent reading of Khrushchev's report to the XX Congress of the CPSU, was accompanied by intense theoretical debates that led to a real flowering of Marxist thought. In Czechoslovakia these debates were particularly relevant and gave rise to a genuine pluralism within the Marxist theory. The work of Jindrrich Zelený, Karel Kosik and Robert Kalivoda represented three distinguished dialogues with the philosophical tradition, with Marx's work and the Marxism, as well as with different existing theoretical and philosophical trends in Czechoslovakia and expressed three different attempts to address the crisis of the official dogmatism.
\end{abstract}

Keywords: Czech Marxism, Jindřich Zelený, Karel Kosik e Robert Kalivoda

\section{I - Introdução}

Pode-se afirmar, que um dos importantes problemas da complexa história do marxismo no século XX são os conceitos de "marxismo soviético", "marxismo oriental", assim como, o conceito especular de "marxismo ocidental"; conceitos que desempenharam um papel importante nas diferentes discussões teóricas e tentativas de reconstrução histórica da tradição marxista do século XX. Estes conceitos, desde o seu surgimento e sucessiva difusão, estão indissociavelmente ligados aos diferentes embates históricos e teóricos ocorridos no interior da tradição marxista; entretanto, apesar de seu uso largamente difundido, a sua utilização de forma generalizada e acrítica, antes de

\footnotetext{
${ }^{1}$ Doutor em Ciências Humanas na área de Filosofia pela Universidade de Varsóvia - Polônia (1996). Professor do Programa de Pós Graduação em Educação (PPGEd) da Universidade Tuiuti do Paraná. Este trabalho é uma versão revista de uma comunicação apresentada no GT Marxismo do $39^{\circ}$ Encontro Anual da ANPOCS realizado em Caxambú - Minas Gerais 2015.
} 
contribuírem à compreensão desta história, constituem um sério obstáculo para a elaboração de uma crítica da experiência teórica marxista do século XX.

É importante sublinhar que o objetivo deste artigo não é a reconstrução desta história em seu conjunto, nem mesmo daqueles referidos conceitos, mas a análise de um momento específico desta história - o do marxismo na Tchecoslováquia nos anos 1960 e, através da identificação de algumas das suas características, procurar indicar a arbitrariedade das reconstruções teóricas fundadas naqueles conceitos.

Com a morte de Stalin, em 1953 e a sucessiva leitura do relatório de Kruschev (Sobre o culto à personalidade e suas consequências) frente ao XX Congresso do PCUS, realizado em fevereiro 1956, desencadeou-se um processo de desestalinização que teve, em ritmos diversos, profundas consequências políticas e sociais em diferentes países da Europa Oriental. Ao contrário da Polônia e da Hungria, que passaram por situações trágicas e profundas transformações políticas em 1956, na Tchecoslováquia transformações de semelhante intensidade irromperam, apenas, após anos de gestação e encontraram o seu apogeu com os acontecimentos da chamada Primavera de Praga em 1968. Durante este período (1955/1956-1968), paralelo às mudanças sociais e políticas, tanto na Europa Oriental, em geral, como na Tchecoslováquia, em particular, ocorreram intensos debates no interior do pensamento marxista e que resultaram em diferentes elaborações teóricas, expressão de um verdadeiro pluralismo teórico. Particularmente importantes foram as contribuições de três destacados jovens pensadores Jindřich Zelený, Karel Kosik e Robert Kalivoda que elaboraram suas obras neste período e que procuraram, a partir de diferentes abordagens, oferecer diferentes respostas a crise do dogmatismo oficial.

Se por um lado, estas obras estão inseridas no conjunto dos debates teóricos marxistas então travados, tanto na Europa Oriental como na Europa Ocidental, como por exemplo: a polêmica sobre a relação do marxismo com a tradição filosófica anterior, em particular, a relação entre Marx e Hegel, sobre o Jovem Marx e o Marx da Maturidade, sobre o Humanismo marxista e o conceito de alienação, sobre a integração do marxismo com diferentes correntes teóricas. Por outro lado, estas obras expressam, igualmente, uma especificidade resultante da situação histórica e teórica tchecoslovaca.

Neste sentido, na tentativa de ressaltar a referida especificidade da situação tchecoslovaca e do desenvolvimento do marxismo tcheco, procurou-se, em um primeiro momento, elaborar uma reconstrução histórica e teórica desta situação, através de uma

\begin{tabular}{|l|l|l|l|l|}
\hline Revista 2 ialectus & Ano 3 & n. 8 & Janeiro - Agosto 2016 & p. 116-133 \\
\hline
\end{tabular}


periodização que procura identificar os principais períodos do desenvolvimento do pensamento marxista na Tchecoslováquia, ao longo do século $\mathrm{XX}^{2}$.

\section{II - Periodização do desenvolvimento do marxismo na Tchecoslováquia no} século XX

1) 1918-1938/1939: Da criação do estado tchecoslovaco até os acordos de Munique em 1938, que levaram a ocupação alemã, ao desmembramento do estado e o consecutivo início da II Guerra Mundial. A Tchecoslováquia, surgida do colapso do Império Austro-húngaro, reunia as regiões da Boêmia, Morávia, Eslováquia e Rutênia sub-carpática (enquanto as duas primeiras estavam entre as regiões mais industrializadas do antigo Império, as duas ultimas eram predominantemente agrárias) ${ }^{3}$; além desta diversidade econômica entre as diferentes regiões, existia ainda uma forte heterogeneidade nacional, que se expressava em uma grande população de origem alemã - a segunda nacionalidade do país. Como sabemos, estas diferenças terão graves consequências no final da década de 1930 e no sucessivo destino da República. Ao contrário dos outros países da Europa Oriental, a Tchecoslováquia era a única democracia parlamentar na região e contava com um forte Partido Comunista legal, que se encontrava entre os maiores Partidos Comunistas da Europa (em particular, entre os anos 1922-1928) ${ }^{4}$. O marxismo estava, antes de tudo, presente no interior dos partidos de esquerda, em particular no Partido Comunista. No mundo cultural, o pensamento marxista e de esquerda tinha uma significativa representação intelectual, podem ser nomeados, entre outros, os nomes do grande escritor Jaroslav Hašek (falecido em

\footnotetext{
${ }^{2}$ A presente periodização é uma re-elaboração e extensão para a história da Tchecoslováquia das sugestões desenvolvidas por Leszek Kołakowski, em seu livro Główne Nurty Marksizmu (Correntes Principais do Marxismo), sobre o a evolução do marxismo na Europa Oriental no qual identifica os períodos 1945-1949; 1949-1955; 1955-1968. (Kołakowski, 1988, p. 923). Para maiores informações sobre a filosofia na Europa Oriental em geral, e na Tchecoslováquia em particular, no século XX, cf. (Paganini, 1978, p. 469-517). Para uma divisão mais minuciosa dos anos 1945-1960, cf. (Zanardo, 1974).

${ }^{3}$ Em 1930, por exemplo, na parte tcheca o percentual da população total ocupada em atividades agrícolas era de $25,5 \%$ e na indústria 39,5\%, enquanto na Eslováquia correspondiam a 56,7 \% e 17,8\%; números, estes, que bem demonstram a heterogeneidade entre as duas diferentes regiões do estado tchecoslovaco. (Tomaszewski, 1987, p. 60).

${ }^{4}$ Em 1924 o Partido Comunista da Tchecoslováquia era, em número de filiados o segundo maior partido da Internacional Comunista com 130.000 membros (enquanto PC da Alemanha reunia 350.000 e o da França 50.000) e percentualmente era o maior PC europeu (reunia 9 membros por mil habitantes enquanto o da Alemanha 5,35). (Kriegel, p. 126-127). Para outras informações sobre o PCT e a crise de 1928 (e seus reflexos entre os intelectuais), cf. (Hájek, 1984, p. 204-208). Para algumas informações sobre o PCT e a Socialdemocracia na Tchecoslováquia, consultar igualmente: (Cole, 1986, p. 214-222; Cole, 1975, p. 186).
}

\begin{tabular}{|l|l|l|l|l|}
\hline Q Rovista Dialectus & Ano 3 & n. 8 & Janeiro - Agosto 2016 & p. 116-133 \\
\hline
\end{tabular}


1923); do destacado representante do surrealismo Karel Teige; do poeta surrealista Vítěslav Nezval; do escritor, dramaturgo e cineasta Vladislav Vančura (que foi expulso do PCT em 1928); do historiador e musicólogo Zdeněk Nejedlý (futuro teórico da política cultural do PCT após a II Guerra Mundial); do jornalista, crítico literário e de teatro Kurt Konrad (crítico do estruturalismo tcheco), do também jornalista, crítico literário e teórico marxista Eduard Urx - que deixou diversos escritos sobre filosofia e filosofia tcheca; do crítico literário e teórico marxista, Bedřich Václavek e do escritor e dirigente político Jan Šverma. Entretanto, esta forte presença cultural, não encontrava uma correspondência no mundo universitário e filosófico, aonde a hegemonia era de pensadores estranhos ao marxismo, aonde se fazia sentir, por um lado, a forte presença da figura do presidente da República Tchecoslovaca, Thomas Masaryk ${ }^{5}$ e de várias tendências da filosofia positivista e, por outro lado, das duas instituições de grande peso teórico e intelectual existentes em Praga, o Círculo Linguístico de Praga, expressão do estruturalismo linguístico ${ }^{6}$ (entre seus membros é importante destacar: Vilém Mathesius, Nikolai Trubetskoy, Roman Jakobson, René Wellek e Jan Mukařovský) e o Círculo Filosófico de Praga (Cercle philosophique de Prague pour les recherches sur l'entendement humain $)^{7}$ que tinha uma forte influência da fenomenologia de Husserl e que reunia destacados filósofos das universidades tcheca e alemã de Praga ${ }^{8}$ (Emil Utitz, Jan Blahoslav Kozák, Jan Patočka e Ludwig Landegreb). Foi frente ao Círculo que, em 1935, Edmund Husserl proferiu suas famosas conferências sobre a Crise da Ciência Europeia que tanto influenciaram a filosofia do século XX. (Husserl, 2012) ${ }^{9}$

\footnotetext{
${ }^{5}$ Como é sabido, Masaryk em fins do século XIX tinha publicado o livro Die philosophischen und soziologischen Grundlagen des Marxismus - Studien zur sozialen Frage, anunciando a "crise do marxismo". Labriola, no mesmo ano de 1999 escreveu uma crítica a este livro. Um artigo de Masaryk e a resposta de Labriola pode ser consultados em: (Labriola, 2010). Um testemunho, sobre a importância de Masaryk e da vida cultural de Praga, nos é dado por Jan Mukařovský (1969, p. 68): "Após a primeira guerra mundial, um enorme élan cultural nasceu do colapso austro-húngaro. O Império, o estado austro húngaro era um muro que nos separava do resto do mundo. Nós nos viramos então em direção da França. Praga era um lugar aonde um filósofo era chefe de estado e um filósofo da linguagem."

${ }^{6} \mathrm{O}$ estruturalismo do Círculo Linguístico de Praga tentou desde o seu início superar as "barreiras intransponíveis entre os métodos sincrônicos e diacrônicos como fez a Escola de Genebra". (Mathesius, 1969, p. 23). Sobre esta importante questão metodológica, cf. (Mathesius, 1969, p. 23-24). Sobre o estruturalismo Tcheco, consultar também: (Mukařovský, 1969, p. 54-59; Mukařovský, 1988, p.135-148).

${ }^{7}$ Para algumas informações sobre o Círculo Filosófico de Praga, cf. Rezek, 1990/1991, p.103-115).

${ }^{8}$ Entre 1882 e 1945 existiram em Praga a Universidade boêmia/tcheca (Univerzita Karlova) e a Universidade alemã (Karl-Ferdinands-Universität). A página da Faculdade de Filosofia da Universidade Masaryk (FF MU) em Brno dispõe de um importante dicionário de autores filósofos tchecoslovacos e outras informações correlatas, que foram uma importante fonte de informações para o presente trabalho: www.phil.muni.cz

${ }^{9}$ Estes escritos de Husserl irão encontrar uma ampla recepção na filosofia tcheca, entre os autores analisados no presente artigo é importante destacar a influencia na reflexão de Karel Kosik, assim como, a análise da obra de Husserl desenvolvida por Jindřich Zelený (1982, p. 100-122).
}

\begin{tabular}{|l|l|l|l|l|}
\hline Q Ronista Dialeatus & Ano 3 & n. 8 & Janeiro - Agosto 2016 & p. 116-133 \\
\hline
\end{tabular}


Esta situação dual, entre a presença cultural do marxismo e a situação da filosofia marxista e de sua influência na Universidade, situação esta que terá, ainda, consequências nos primeiros anos sucessivos a II Guerra Mundial foi bem sintetizada por Gianni Paganini:

O marxismo, no período antecedente ao segundo conflito mundial, não apresentava um desenvolvimento filosófico de relevo, já que era ligado diretamente a ação política ou se articulava na estética e na filosofia da cultura. (Paganini, 1978, p. 487) ${ }^{10}$

2) 1938/1939 -1945: Dos acordos de Munique em 1938 e início da II Guerra Mundial até o final da II Guerra Mundial. Após a anexação dos sudetos pela Alemanha nazista e o definitivo desaparecimento da República tchecoslovaca em 1939, inicia-se um periodo de intensa repressão as diferentes organizações de resistência ao nazismo. Um significante número de intelectuais de esquerda e marxistas irão morrer durante este período, entre eles, Kurt Konrad, Eduard Urx e Vladislav Vančura (assassinados pelos nazistas), Bedřich Václavek (morto em Auschwitz) e Jan Šverma (tombado em combate após a Insurreição nacional eslovaca). Futuros membros da nova geração, como por exemplo, Karel Kosik e Radovan Richta foram prisioneiros no Campo de Concentração de Terezín, como militantes da organização ilegal comunista $P_{\check{r}}{ }^{2} v v^{11}{ }^{11}$.

3) 1945-1948: Do final da II Guerra Mundial até a tomada do poder pelo PCT em fevereiro de 1948. Novamente neste período se expressa uma distinção entre a evolução política da Tchecoslováquia e dos outros países da Europa Oriental. A posição assumida pelos países ocidentais (em particular Inglaterra e França) durante os Acordos de Munique de 1938, a perda de influência dos partidos de direita durante a Guerra e uma forte presença do Partido Comunista na sociedade - em setembro de 1945 chegou a 700.000 filiados e nas eleições de 1946 foi o partido mais votado com $43 \%$ dos votos na parte tcheca e $30 \%$ na Eslováquia - contribuíram para que nesse período ocorressem um conjunto de mudanças políticas e sociais sem grandes confrontos políticos. ${ }^{12}$ Este período caracterizou-se pela existência de um pluralismo político e cultural, que no

${ }^{10}$ Segundo Paganini, entre os poucos filósofos marxistas do pré-guerra, devem ser nomeados Ludvík Svoboda, estudioso da filosofia antiga, escreveu sobre a filosofia na URSS e traduziu em 1933 Materialismo e Empiriocriticismo e o eslovaco Ladislav Szántó.

${ }^{11} \mathrm{O}$ artigo de Ondřej Matějka (2012, p. 112-116) está voltado principalmente para a socióloga da religião Erika Kadlecová, traz um conjunto de informações sobre os intelectuais desta mesma geração e que pertenceram a organização Předvoj.

${ }_{12}$ Para uma reconstrução deste período (Fejtö, 1972a, p. 7—84, 184-187, 208-221; Tomaszewski, 1992, p. 28-31, 64-70; Tomaszewski, 1987 p. 60-70).

\begin{tabular}{|l|l|l|l|l|}
\hline Q Rovista Dialectus & Ano 3 & n. 8 & Janeiro - Agosto 2016 & p. 116-133 \\
\hline
\end{tabular}


entanto se atenuou gradualmente com o início da guerra fria. No campo da filosofia, como observou Aldo Zanardo em seu escrito sobre a filosofia marxista na Tchecoslováquia, a situação é em linhas gerais semelhante a situação anterior à guerra. Entre os poucos filósofos marxistas, podemos lembrar os nomes, do já citado Ludvík Svoboda e do filósofo das ciências naturais e lógico matemático Arnošt Kolmann, que temporariamente neste período (1945-1948), retornou da URSS. Reaparecem, igualmente, as publicações dos clássicos do marxismo.

Zanardo caracteriza com as seguintes palavras a situação da filosofia marxista neste período:

Se produz, talvez em um modo ainda mais limitado, um estado de coisas não diferente daquele anterior a guerra, quando a reflexão filosófica marxista não tinha propriamente uma autonomia em relação a reflexão e a prática política e a reflexão historiográfica ou literária, e quando a literatura, a arte, a história e a sociologia da literatura constituíam a parte preponderante da cultura marxista. (Zanardo, 1974, p. 370-371) $)^{13}$

4) 1948/1949-1954: Da tomada do poder pelo PCT em fevereiro de 1948 até o início do processo de desestalinização. Período de intensas transformações econômicas - industrialização pesada, coletivização da terra, um forte esforço para a redução das diferenças econômicas entre a parte tcheca e eslovaca da república - e políticas que vieram acompanhados dos processos contra os "nacionalistas eslovacos" e contra antigos dirigentes do PCT (Clementis, Slanský, entre outros acusados e condenados a morte e a prisão). ${ }^{14}$ Corresponde, igualmente, a um momento de unificação cultural e ideológica, no qual a síntese filosófica soviética fortemente dogmatizada transforma-se em filosofia oficial. Esta transformação ocorreu, em muitos momentos, com o recurso a métodos administrativos e coercitivos, entre os quais, o afastamento da atividades pedagógicas e transferência da Universidade para outras instituições de pesquisa de antigos professores, um exemplo é Jan Patočka. Importantes acontecimentos deste período, no terreno da cultura e da filosofia, foi a criação do Instituto de Filosofia da

${ }^{13} \mathrm{O}$ artigo de Zanardo, é em grande parte, uma resenha crítica do livro de Nicolas Lobkowicz, Marxismus-Leninismus in der ČSR. Die tschechoslowakische Philosophie seit 1945 publicado em 1961 na coleção Sovietica dirigida pelo frade dominicano Józef Maria Bocheński e está dividido em duas partes uma parte histórica (I) e uma parte sistemática (II) e contém uma extensa bibliografia como também curtas referencias biográficas sobre um conjunto de autores. Este artigo de Zanardo é uma versão revista e ampliada de um artigo anterior (Zanardo, 1963, p. 133-147).

${ }^{14}$ Para maiores informações sobre este período: Fejtö, 1972a, p. 281-288; Tomaszewski, 1987, p. 70-75).

\begin{tabular}{|l|l|l|l|l|}
\hline Q & Jonista \\
\hline
\end{tabular}


Academia de Ciências da Tchecoslováquia (Filosofický ústav ČSAV) em $1953^{15}$ e a publicação, por esta instituição, da revista filosófica Filosofický Časopis. Neste período, alguns filósofos tradicionais se aproximaram do marxismo, entre os quais podemos citar, Emil Utitz - prisioneiro durante a guerra no campo de concentração de Terezín-, Ladislav Rieger, Igor Hrušovský, Jiřina Popelová-Otáhalová e Jan Mukařovský. ${ }^{16}$ Uma grande importância foi dada à formação de uma nova geração ${ }^{17}$ de pensadores marxistas - a chamada geração média "Mittlere Generation" como a nomeou Lobkowicz - que irão desempenhar um papel decisivo nos anos sucessivos: Jindřich Zelený, Karel Kosik, Robert Kalivoda, Radovan Richta, Ladislav Tondl, Ivan Dubský, Ivan Sviták e Josef Zumr, entre outros. ${ }^{18}$ Uma das características comuns da Tchecoslováquia com outros países da Europa Oriental, além do ensino da filosofia marxista e do desenvolvimento da luta ideológica foram os diferentes projetos de pesquisa, de grande importância, voltados a resgatar as tradições democráticas e revolucionárias, assim como, da história do pensamento filosófico nos diferentes países da Europa Oriental, iniciados neste período e que se estenderam até o período seguinte.

5) 1955-1968: Do início do processo de desestalinização a Primavera de Praga. ${ }^{19}$ Assim como em outros países da Europa Oriental, também na Tchecoslováquia se fizeram sentir, mas em um ritmo mais lento, os efeitos da desestalinização incentivados, entre outros acontecimentos, pelos XX Congresso do PCUS (1956) e XXII Congresso do PCUS (1961). Os primeiros sinais de uma crise econômica se manifestaram nos primeiros anos da década de 1960. Este quadro se acentuou também com as reivindicações nacionais eslovacas; entretanto, as mudanças políticas só iniciaram verdadeiramente em 1967 e se aceleraram em 1968, com a substituição de Novotny por Dubček na secretaria geral do PCT, que abrirá o período da Primavera de Praga e se

\footnotetext{
${ }^{15}$ Sobre as condições privilegiadas de trabalho na Academia de Ciências, cf. (Matějka, 2012, p.116ss.)

${ }^{16}$ Sobre a aproximação dos antigos professores ao marxismo e a sua contribuição e limites para o desenvolvimento da filosofia marxista na Tchecoslováquia (Zanardo, 1974, p.374s.). Como observou, certa vez, o sociólogo polonês Paweł Śpiewak, a viragem à esquerda foi algo vivo entre os intelectuais naqueles anos: "O sentimento de comunidade construído nos fundamentos de uma ideologia progressista baseado nos modelos iluministas, ideologia racional e da reconstrução racional da ordem social era fortemente vivida nos meios intelectuais, em particular na segunda metade dos anos 40." (Śpiewak, 2012, p. 212)

${ }^{17}$ Sobre a importância desempenhada pela jovem geração de filósofos marxistas, cf. o já citado anteriormente: (Zanardo, 1974, p.377s). O mesmo Śpiewak observa, sobre a situação polonesa: "A revolução socialista não foi apenas uma revolução classista, mas também uma revolução geracional". (Śpiewak, 2012, p. 208-209).

${ }^{18}$ Cf. Sobre a trajetória, neste período, de alguns membros da jovem geração o artigo já citado: (Matějka, 2012, p.116ss.)
}

\begin{tabular}{|l|l|l|l|l|}
\hline Q Ronista Dialectus & Ano 3 & n. 8 & Janeiro - Agosto 2016 & p. 116-133 \\
\hline
\end{tabular}


encerrará com a Intervenção militar dos Exércitos do Pacto de Varsóvia, em agosto de 1968. A partir dos anos 1955-56, e em diferentes ritmos, no campo cultural ocorrem transformações graduais, que se intensificarão a partir dos anos 1960 e desempenharão uma importância fundamental nos acontecimentos sucessivos. ${ }^{20}$ Constituem-se, igualmente, Comissões e Grupos de Pesquisa voltados a investigação de importantes aspectos da sociedade; entre estes Grupos de Pesquisa e Comissões podemos enumerar: a Comissão dedicada as reformas econômicas dirigida por Ota Šik, as reformas políticas chefiada por Zdenek Mlynář e o dedicado a análise da Revolução Científico-técnica e dos impactos que tinha a sua frente Radovan Richta; como é sabido, estes três personagens irão assumir importantes funções públicas ou como assessores durante os meses de $1968 .^{21}$ Este período corresponde, no terreno filosófico, a um processo de intensa crítica ao dogmatismo existente no período anterior e que levou ao surgimento e cristalização de diferentes concepções concorrentes no interior da filosofia marxista, algumas das quais evoluíram para posições revisionistas, que serão nomeados na Tchecoslováquia como "Revisionismo positivista" e "Revisionismo neohegeliano", distinção esta a qual retornaremos abaixo. O debate teórico em torno destas concepções marcará em grande parte o período e envolveu numerosos filósofos formados no período anterior. Entre os principais representantes da nova geração de filósofos na Checoslováquia e que irão desempenhar um importante papel neste período, estão os já citados: Jindřich Zelený, Karel Kosik e Robert Kalivoda.

6) 1969-1989: Da Intervenção militar a Restauração capitalista em $1989 .{ }^{22} \mathrm{O}$ período é marcado pelo processo de "normalização" iniciado em 1969 com a substituição de Dubček por Gustáv Husák, no cargo de Secretário Geral e é acompanhado de um grande número de expulsões de membros do partido (1/3 do total de membros, segundo algumas fontes) e afastamento do trabalho e da vida pública de

\footnotetext{
19 (Fejtö 1972b, p.190-196; 245-283; Tomaszewski, 1992, p. 233-235, 254-257, 286-296; Tomaszewski, 1987, p. 75-84).

${ }^{20}$ Como exemplos de acontecimentos emblemáticos destas mudanças no campo cultural podemos enumerar, entre outros, em 1963 o III Congresso da União de Escritores Tchecoslovacos e o Congresso realizado em Liblice dedicado a Franz Kafka; em 1967, o particularmente turbulento, IV Congresso da União de Escritores Tchecoslovacos. Para uma análise da sobre o peso e a importância da intelectualidade na sociedade tcheca e do seu papel de oposição política neste período, consultar o livro de Antonin Liehm (1974). Cf. igualmente, a partir de um ponto de vista crítico sobre as raízes pequeno burguesas do revisionismo, as observações de Ladislav Hrzal (1974, p.73-96).

${ }^{21}$ Para maiores informações sobre estes Grupos de Pesquisa e Comissões, sobre o papel dos "experts" e dos conflitos entorno deles, cf. (Matějka, 2012, p. 137-140; Claudín 1983, p. 188-189. Sobre a participação destes intelectuais na elaboração do Programa de Ação do PCT, cf. (Mlynáŕ, 1988, p. 59ss; 69-70).

22 (Fejtö, 1972b, p. 285-315).
}

\begin{tabular}{|l|l|l|l|l|}
\hline Qevista Qialectus & Ano 3 & n. 8 & Janeiro - Agosto 2016 & p. 116-133 \\
\hline
\end{tabular}


grande parte da intelectualidade que tinha apoiado ativamente a Primavera de Praga, um grande número deles abandonará o pais nos anos seguintes. ${ }^{23}$ Em escala internacional, a repercussão dos acontecimentos de 1968 tiveram graves consequências para o marxismo e o movimento comunista internacional, como a crescente queda de popularidade, em ritmos diferentes segundo os diferentes países. (Kołakowski, 1988, p. $923)^{24}$ No campo da filosofia, o período é caracterizado pela derrota das diferentes correntes revisionistas e da corrente intermediária. Continuam a sua atuação Radovan Richta - que tinha apoiado ativamente a política de Dubček e que será vivamente censurado pela escolha de apoiar o novo governo de Husák - e J. Zelený ${ }^{25}$. Entre os anos de 1969 e 1989, Kosik não participará de nenhuma atividade publica e não publicou nenhum escrito, com exceção da sua carta endereçada a Jean Paul Sartre, publicada no jornal Le Monde em 1975, na qual denunciava o confisco de seus manuscritos filosóficos "Sobre a Verdade" e "Sobre a Pratica", que seriam posteriormente devolvidos ao autor. Durante estes anos, Kosik se dedicou exclusivamente à reflexão filosófica e à redação destes manuscritos, que permaneceram inéditos.

7) a partir de 1989, como resultado da desmontagem do "socialismo real", a vida política e intelectual passou a ser dominada por uma virulenta retórica anticomunista ${ }^{26}$, como consequência houve um forte refluxo do pensamento marxista, tornando-se, por alguns anos, um fenômeno intelectual praticamente marginal. Dos antigos filósofos, podemos citar a intensa atividade publicística de caráter crítico desenvolvida por Kosik $^{27}$ após 1992 e que se prolongou até a sua morte em 2003, reunida em diferentes

\footnotetext{
${ }^{23}$ Uma situação semelhante irá ocorrer na Polônia, após os acontecimentos do março polonês 1968 que foi acompanhada de uma maciça emigração e da sucessiva diminuição do poder de atração do marxismo junto a sociedade e intelectualidade polonesas. (Śpiewak, 2012, p.234-236).

${ }^{24}$ A posição excessivamente critica e parcial assumida por Kołakowski, leva-o em diferentes passagens a julgamentos simplificatórios, esta posição marcadamente ideológica, choca-se entretanto com a necessidade de uma análise mais equilibrada e aprofundada. Surgimento de novos pensadores marxistas. Um fenômeno ideológico e patológico, deste período, descrito pelo marxista polonês Stanisław Rainko foi o chamado "marxismo cortesão": "Um produto marginal será a elaboração de um marxismo degenerado, o 'marxismo cortesão', que vive dos favores e da mesa dos senhores, e cujo lema é o total e completo oportunismo, isto é a falta de qualquer convicção própria e opção valorativa”. (Rainko, 1989, p. 186).

${ }^{25}$ De Zelený, consultar a coletânea de artigos do período (Zelený, 1982).

${ }^{26}$ O sociólogo polonês Stanisław Kozyr-Kowalski caracterizou a retórica anti-comunista como: "um instrumento de falsificação da realidade contemporânea e histórica, forma de cegueira e auto-cegueira". (Kozyr-Kowalski, 2004, p. 343); para uma análise da referida retórica: cf. também (Kozyr-Kowalski, 2004, p. 342ss). Para uma análise, do anticomunismo militante de Vaclav Havel, cf. o contundente subcapítulo "Devons-nous vraiment adorer Václav Havel?" (Parenti, 2013, p.115-117); para uma análise das suas concepções políticas conservadoras (Gasparini, 1997, p.62-80).

${ }^{27}$ Alguns escritos do último período da obra de estão reunidos nas coletâneas seguintes: La Crise des
}

\begin{tabular}{|l|l|l|l|l|}
\hline Q Ronista Dialectus & Ano 3 & n. 8 & Janeiro - Agosto 2016 & p. 116-133 \\
\hline
\end{tabular}


coletâneas, na qual não cessa de interrogar criticamente o "mundo na época da globalização". Zelený, por sua vez, continua seus estudos de filosofia e lógica, dando um especial atenção a lógica para-consistente que foram reunidos em um livro traduzido para a língua alemã.

\section{III- Marxismo Tcheco nos anos 1960: algumas observações}

Entre a intensa produção teórica do marxismo tchecoslovaco dos anos 1960 podemos, em particular, destacar as obras dos já citados Jindřich Zelený ${ }^{28}$ (A Estrutura Lógica de 'O Capital' de Marx - 1962/1968), Karel Kosik ${ }^{29}$ (Dialética do Concreto 1963 e A Nossa Crise Atual - 1968) e Robert Kalivoda ${ }^{30}$ (A Realidade Espiritual Moderna e o Marxismo - 1968), três diferentes tentativas de solucionar os problemas postos pelo dogmatismo oficial - a "síntese filosófica do período stalinista" e, que representam três programas teóricos diversos baseados em diferentes relações com a tradição filosófica, com a tradição marxista e com as diferentes correntes culturais e filosóficas.

$\mathrm{Na}$ sequência, procurar-se-á retomar e aprofundar algumas características mais gerais da situação do período, assim como, indicar, brevemente, os aspectos mais gerais destes diferentes programas.

1. Como já foi observado em nossa periodização, na Tchecoslováquia como em

Temps Modernes: Dialectique de la Morale (Kosik, 2003) e Un filosofo in tempi di farsa e di tragedia Saggi di pensiero critico 1964-2000. (Kosik, 2013)

28 Jindřich Zelený nasceu em 1922 Bítovany (Chrudin) em 1922 e morreu em Praga em 1997. Estudou Filosofia e Sociologia na Universidade Carlos. Dedicou-se inicialmente a um trabalho de divulgação da teoria marxista. Sua obra é reconhecida por sua extensa e sólida erudição e esta marcada pela preocupação com problemas da Lógica. A sua principal obra A Estrutura Lógica de 'O Capital' de Marx foi traduzida para uma série de línguas estrangeiras. Cf: https://www.phil.muni.cz/fil/scf/komplet/zeleny.html

${ }^{29}$ Karel Kosik nasceu em Praga em 1926 e morreu em 2003. Preso pela Gestapo em novembro de 1944, por sua militância na organização comunista ilegal Předvoj. Realizou seus estudos na Universidade Carlos de Praga (1945-1947), e entre 1947 e 1949, nas Universidades de Leningrado e Moscou. Pesquisador do Instituto de Filosofia da Academia de Ciências da Tchecoslováquia (FÚ ČSAV). Autor de Dialética do Concreto, um dos livros de filosofia da Europa Oriental mais traduzido durante o século XX. Após os acontecimentos de 1968 é afastado das suas atividades. A partir de 1992 autor de uma série de ensaios dedicados a diferentes problemas da contemporaneidade reunidos em diferentes coletâneas. Cf: https://www.phil.muni.cz/fil/scf/komplet/kosik.html

${ }^{30}$ Robert Kalivoda nasceu em Praga em 1923 e morreu em 1989 no Sanatório na Pleši. Estudou filosofia na Universidade Carlos, no início dos anos 1950 trabalhou no Ministério da Educação e entre 1954-1970 pesquisador do Instituto de Filosofia da Academia de Ciências da Tchecoslováquia (FÚ ČSAV), aposentado em 1974 pela sua intensiva participação na Primavera de Praga. Influenciado pelo surrealismo e pelo estruturalismo tcheco, dedicou-se ao estudo do movimento hussita ao qual dedicou inúmeros trabalhos, entre os quais Husitská ideologie em 1961 (pelo qual foi laureado com um prêmio nacional em 1962). Cf: https://www.phil.muni.cz/fil/scf/komplet/kalivo.html

\begin{tabular}{|l|l|l|l|l|}
\hline Qevista Dialectus & Ano 3 & n. 8 & Janeiro - Agosto 2016 & p. 116-133 \\
\hline
\end{tabular}


outros países da região, a existência de uma tradição intelectual e filosófica estranha ao marxismo representou um obstáculo para a implantação do marxismo como teoria nas Universidades. Este obstáculo inicial, agravou-se ainda mais pelas características próprias da filosofia dominante na URSS, transplantada para os países da Europa Oriental. O já citado Zanardo observa: “esta cultura filosófica - o marxismo, largamente dogmatizado, não soube propor-se como o grande pensamento que represente um grande polo de atração" (Zanardo, 1974, 371). E observava ainda, que nos primeiros anos, a "teoria-divulgação" era claramente privilegiada em detrimento da "teoria-investigação" (Zanardo, 1974, 371).

2. Com a morte de Stalin e a sucessiva desestalinização surgem diferentes críticas a síntese filosófica então dominante na União Soviética e nos países da Europa Oriental. As criticas endereçadas à síntese oficial levou rapidamente ao surgimento de diferentes tendências filosóficas autônomas, que em grande parte das vezes procurava combinar o marxismo com diferentes correntes filosóficas dominantes na Europa Ocidental, como o existencialismo e o neo-positivismo o que davam origem a diferentes formas de ecletismos. Um dos traços característicos do marxismo, neste período, foi a intensa polêmica filosófica, envolvendo "dogmáticos", "anti-revisionistas" e os diferentes "revisionismos", que se aproximavam de uma concepção antropológica da filosofia ou de uma filosofia da natureza. ${ }^{31} \mathrm{Na}$ Tchecoslováquia essas correntes foram nomeadas correspondentemente "Revisionismo neohegeliano" e "Revisionismo positivista". Por fim, uma importante preocupação de inúmeros filósofos foi, justamente, superar esta polaridade entre estas duas correntes opostas e procuraram reafirmar a autonomia da

\footnotetext{
${ }^{31}$ Uma analise aprofundada destes importantes debates para a história do marxismo no século XX, infelizmente, ultrapassaria os limites da presente comunicação; entretanto, algumas referências, sobre esta questão, são indispensáveis. György Márkus observa que como resultado da desestalinização teriam surgido em oposição a síntese filosófica oficial - a "tendência extensional", se constituiu além das duas correntes filosóficas opostas citadas (a "cientificista", que privilegiava uma reflexão metodológica sobre as ciências naturais e a outra, a "ideológica-crítica", que identificava a filosofia como uma visão do mundo voltada à crítica das ideologias), uma terceira corrente a "ontologia social" - que seria representada por Lukács. (Márkus, 1974, p.113-129). Władyslaw Krajewski, por sua vez, caracterizou as duas referidas correntes como: scientific philosophers e antropological philosophers, sendo que a primeira seguia a tradição materialista e positivista e procurava desenvolver o materialismo dialético e a segunda prosseguia a tradição da filosofia clássica alemã e também em alguns casos o existencialismo e a fenomenologia e procuravam desenvolver o materialismo histórico. (Krajewski, 1966, p. XIV-XIX). Entretanto, como observam Mejbaum e Zukrowska, estas duas correntes se distanciaram gradualmente tanto do materialismo dialético como do materialismo histórico, abandonando todo projeto de reconstrução e elaboração de uma filosofia marxista. Enquanto os scientific philosophers passaram a ocupar-se de diferentes disciplinas cientificas e da metodologia das ciências, os antropological philosophers se voltaram à Sociologia empírica e à história do pensamento social. (Mejbaum; Zukrowska, 1985, p.252-253). Por sua vez, Adam Schaff procura relacionar esta cisão, a clássica cisão entre duas
}

\begin{tabular}{|c|c|c|c|c|}
\hline Qevista Dialectus & Ano 3 & n. 8 & Janeiro - Agosto 2016 & p. $116-133$ \\
\hline
\end{tabular}


filosofia marxista.

3. Se por um lado, as obras de Kosik, Kalivoda e Zelený se inserem no interior dos debates travados, tanto na Europa Oriental e Ocidental (entre outras, as polêmicas sobre a relação do marxismo com a tradição e em particular a relação Marx e Hegel, sobre o Jovem Marx e o Marx da Maturidade e sobre o Humanismo marxista, sobre a integração do marxismo com outras correntes teóricas) ${ }^{32}$; por outro lado, estes debates adquiriram um contorno específico na Tchecoslováquia, em parte, resultante das diferentes tendências teórico-filosóficas existentes nos séculos XIX-XX. Os livros de Kosik e Kalivoda, com diferentes intensidades, estão voltados a uma leitura que valorizam os aspectos humanistas da obra de Marx.

4. A obra de Kosik estabelece uma estreita relação com toda uma tradição cultural e filosófica, em particular, com Hegel e a filosofia clássica alemã, assim como, com a fenomenologia contemporânea (Husserl e Heidegger). A sua leitura de Marx se destaca pela utilização, ao lado dos Manuscritos de 1844 e de $O$ Capital, de um conjunto de referências até então pouco usuais na bibliografia marxista, como por exemplo: os Grundrisse, a $1^{\text {a }}$ edição de 1867 de O Capital e as Notas Marginais sobre Wagner. No interior do marxismo se aproxima, entre outros, de Lukács e de pensadores do marxismo francês (Sartre e Lefebvre); estão igualmente presentes as referências à tradição literária universal e tcheca (Goethe, Kafka ${ }^{33}$ e Hašek, entre outros). Estruturado em quatro capítulos o livro Dialética do Concreto, atribui uma importância central aos conceitos de Práxis e Totalidade. O seu projeto teórico está voltado a destruição do mundo da pseudoconcreticidade - mundo cotidiano e imediato tal como se apresenta. Kosik desenvolve um conjunto de críticas as diferentes conceitos reificados da filosofia e das Ciências Humanas: Cura (Sorge) de Heidegger, homo oeconomicus e fator econômico que representam exemplos de distintas concepções reificadas do mundo da

tradições que perpassaria toda a história da filosofia, a tradição jônica e a tradição socrática. (Schaff, 1965, p.11ss).

32 Uma análise sistemática, das semelhanças e diferenças entre as distintas respostas teóricas ao dogmatismo, procuradas pelo marxismo tanto no Ocidente como no Oriente, são particularmente importantes para demonstrar a arbitrariedade do conceito de "marxismo ocidental".

33 É importante lembrar que no mesmo ano da publicação de Dialética do Concreto, foi realizado no Castelo de Liblice uma importante Conferência dedicada a obra de Kafka, que representou um marco para uma nova recepção marxista da obra de Kafka e, também um importante momento na liberalização cultural nos anos 1960. Kosik apresentou neste congresso um trabalho dedicado a Kafka e Hašek: "Hašek contro il 'grande meccanismo"”. (Kosik, 2013, p.81-92). Anos depois, lembrando deste congresso, em uma entrevista com Antonio Cassuti, observa: "nos anos 1960 (conferência de Liblice) a obra de Kafka era uma ocasião e um pretexto para a crítica e a análise do presente". (Kosik, 2003, p. 143). O mesmo Kosik, referindo-se a Kafka, observa na Dialética do Concreto “... a obra de Franz Kafka pode ser entendida como destruição artística da pseudoconcreticidade.” (Kosik, 1976, p.78).

\begin{tabular}{|l|l|l|l|l|}
\hline Qevista Dialectus & Ano 3 & n. 8 & Janeiro - Agosto 2016 & p. 116-133 \\
\hline
\end{tabular}


pseudoconcreticidade. Em sua análise da obra de Marx procura discutir diferentes aspectos do projeto teórico marxista, a partir de uma leitura de $O$ Capital, assim como, das relações entre esta obra e o Jovem Marx. Procura aproximar a estrutura de $O$ Capital a toda uma tradição teórica, a tradição da odisseia, do "romance de formação" (Bildungsroman) - cujo um dos exemplos seria a Fenomenologia do Espírito de Hegel.

5. Kalivoda, ao contrário, se filia a uma tradição crítica a Hegel e ao hegelianismo e privilegiava uma corrente anti-hegeliana que recuava ao pedagogo e filósofo alemão Johann Friedrich Herbart e ao herbatismo (muito influente durante o século XIX nos países tchecos), assim como, a tradição estruturalista do Círculo Linguístico de Praga e, em particular a Jan Mukařovský. ${ }^{34}$ Atribuía, igualmente, uma grande importância a longa tradição, do que chama libertinismo (ideal humanístico de liberdade de tipo jacobino) e ao romantismo revolucionário - que também é objeto de atenção em sua obra sobre o movimento hussita ${ }^{35}$. O livro de Robert Kalivoda La realtà spiritual moderna e il marxismo está dividido em três capítulos. No primeiro capítulo dedicado ao estruturalismo e a estética, Kalivoda desenvolve uma crítica da estética marxista de origem hegeliana e contrapõe a eala uma estética desenvolvida sob influência do estruturalismo tcheco. O segundo capítulo (Marx e Freud) está voltado a uma análise da contribuição de Freud e outros psicanalistas e teóricos (Fromm, Marcuse, surrealistas) para a elaboração de uma Antropologia Filosófica, para a elaboração de uma filosofia marxista do homem. Nestes dois primeiros capítulos está muito presente o projeto de estabelecer uma síntese, uma integração entre o estruturalismo, a Psicanálise e o marxismo. O terceiro capítulo, por sua vez, está dedicado ao libertinismo e a tradição romântico revolucionária que se constituiria como uma corrente percursora direta da tradição marxista. É curioso destacar que o projeto de Kalivoda, partindo de referências, em parte, próximas a de Althusser chega a resultados teóricos opostos. (Kalivoda, 1971). A sua leitura de Marx está fortemente marcada, pelo recurso a algumas

\footnotetext{
${ }^{34}$ Kalivoda no primeiro capítulo "La dialettica dello strutturalismo e la dialettica dell"estetica" do seu livro anteriormente citado, partindo das análises de outro jovem filósofo tcheco Josef Zumr, destaca a filiação entre o pensamento de Herbart e o pensamento estético e estruturalista tcheco: “ (...) a corrente herbartiana encontra a sua clássica concretização própria na evolução da estética tcheca e desemboca no estruturalismo tcheco (...)". (Kalivoda, 1971, p.43). A retomada desta tradição permitiria, segundo Kalivoda, elaborar uma crítica da "estética conteudista" de filiação hegeliana e que era hegemônica no "período do dogmatismo". (Kalivoda, 1971, p.43-49).

${ }^{35}$ Os conceitos de jacobinismo e romantismo, entretanto, são estendidos para bem além dos seus limites históricos, se transformando em uma "atitude", uma "disposição". Esta concepção lembra, por exemplo, a concepção de romantismo defendida por Michael Löwy, alias outro defensor da importância da tradição surrealista. Uma referência a obra de Kalivoda dedicada a Hus (no qual já identificava uma forma de Filosofia do Homem) e ao movimento hussista pode ser encontrada em: (Zumr, 1963a, p. 11).
}

\begin{tabular}{|l|l|l|l|l|}
\hline Qevista Dialectus & Ano 3 & n. 8 & Janeiro - Agosto 2016 & p. 116-133 \\
\hline
\end{tabular}


fragmentos referentes ao conceito de natureza humana (e não essência humana) ${ }^{36}$ presentes nos Manuscritos de 1844, na Ideologia Alemã (sobre a fixidez dos desejos e pensamentos) (Marx; Engels, 2007, p.288-289) e no Livro III de O Capital (a passagem do reino da liberdade para o reino da necessidade) (Marx, 1983, p. 273), no campo do marxismo destaca as suas referências as obras de Erich Fromm e Herbert Marcuse, em particular pela importância que tinham atribuído ao pensamento de Freud. Nas artes se filiava a Karel Teige e a importante tradição surrealista tcheca. Procurava igualmente estabelecer um diálogo ("integração") com o pensamento de Freud e a Psicanálise. Se por um lado, os dois autores se aproximam em uma valorização de diferentes versões do humanismo marxista, entre eles, existe uma clara distinção quanto a importância a ser atribuída aos conceitos de alienação, fetichismo e filosofia da práxis, no tocante a relação Marx - Hegel, sobre a concepção de arte ("conteudista" ou "formalista"), assim como, sobre o estruturalismo. ${ }^{37}$

6. Por último, a obra de Zelený ${ }^{38}$ se distancia claramente dos dois projetos teóricos anteriores. Próximos a diferentes formas de humanismo marxista, o que não deixará de ter reflexos políticos e na trajetória posterior dos autores. Zelený privilegia a análise da estrutura lógica de $O$ Capital e atribui uma particular importância aos desenvolvimentos da lógica matemática e da teoria das ciências. Em sua relação com a tradição filosofia reserva uma importância, particular, a obra de Kant. Sua obra se caracteriza por uma minuciosa leitura da obra de Marx, tanto dos escritos do jovem Marx, a Ideologia Alemã (com uma atenção especial à crítica de Marx a Stirner), a Miséria da Filosofia, como dos seus escritos econômicos (os Grundrisse, O Capital (incluído a $1^{\text {a }}$ edição de 1867) e as Notas Marginais sobre Wagner. No tocante as relações com o marxismo, é visível a grande importância atribuída aos estudos dedicados aos aspectos teóricos da obra maior de Marx desenvolvidos URSS na esteira

\footnotetext{
36 A distinção entre natureza humana e essência humana desempenha um importante papel na argumentação de Kalivoda, para ele, ao contrário do conceito de natureza humana, o conceito de essência humana "foi realmente abandonado pelo Marx "maduro"”. (Kalivoda, 1971, p. 87).

${ }^{37}$ Kosik retorna em sua obra a crítica endereçadas ao formalismo por Kurt Konrad nos anos 1930, no qual caracterizou o estruturalismo como uma falsa e má totalidade. (Kosik, 1976, p. 52. Para o texto de Konrad: (Konrad, 1975, p. 145-173). Sobre uma aproximação entre Kosik e Kalivoda (não consensual) cf. o já citado: Zumr, 1963a).

${ }^{38}$ O livro de Zelený La Estructura Lógica de 'El Capital' de Marx é uma tradução da edição alemã que reunia duas diferentes obras, a primeira $O$ logické struktuře Marxova Kapitálu (publicada originalmente em 1962) que corresponde, em linhas gerais, a Parte I: Sobre a análise genético-estrutural materialista dialética e a Conclusão: Ser, Prática e Razão e da segunda obra Praxe a rozum. Pojetí racionality a překonání tradiční ontologie v Marxově kritice Hegela que corresponde a parte (II) dedicada A lógica de $O$ Capital e a crítica de Hegel por Marx.
}

\begin{tabular}{|l|l|l|l|l|}
\hline Q Ronista Qialectus & Ano 3 & n. 8 & Janeiro - Agosto 2016 & p. 116-133 \\
\hline
\end{tabular}


das indicações apontadas por Lenin em seu Cadernos Filosóficos. ${ }^{39}$ Zelený está voltado a destacar a obra de Marx como um novo tipo de racionalidade cientifica que se diferenciaria dos dois anteriores "tipos históricos fundamentais de racionalidade" a aristotélica e a científico moderna; este novo tipo de racionalidade é nomeado ontopraxeologia: "o nascimento do marxismo significa a superação da contraposição tradicional de gnoseologia e ontologia em um método filosófico de investigação que é por princípio novo". (Zelený, 1974, p.12) (0 $^{40}$

Neste sentido, particularmente importante revelam-se dois pontos, o primeiro que se refere ao movimento de superação, na trajetória intelectual de Marx, da economia política clássica e da tradição filosófica de Hegel e dos jovens hegelianos:

Foi a crítica da economia política burguesa, levando-se em conta o esquematismo que estava concebida inicialmente, o que permitiu Marx olhar mais aprofundadamente a filosofia de Hegel como acabamento da metafísica tradicional e o que o possibilitou a ruptura com toda filosofia "ideológica" (em particular com a antropologia de Feuerbach e dos jovens hegelianos). Dito de outra maneira: os começos da superação ontopraxeológica da filosofia tradicional, tal como se esboça nas "Teses sobre Feuerbach" e na Ideologia Alemã, pressupõe a atitude crítica em relação a economia política burguesa e a captação da relação que existe entre a forma burguesa da vida individual-social e a metafísica. (Zelený, 1974, p. 295).

O segundo ponto remete ao lugar de $O$ Capital e sua estrutura:

$O$ Capital segue em sua estrutura lógica, antes de tudo, o movimento da sociedade burguesa. $\mathrm{O}$ sujeito de todo processo são em $O$ Capital não os homens, do mesmo modo que tampouco são sujeitos soberanos desse movimento real da sociedade burguesa na sua história, homens que entram nestas ou naquelas relações: o sujeito é o capital como relação e circunstância social, que domina nessa sociedade, como força externa, acima das cabeças dos homens e se realiza por sua mediação. O Capital como objeto específico de investigação, como substância e sujeito ao mesmo tempo, é sem dúvida absolutamente mutável em suas formas, porém é imutável na sua essência. (Zelený, 1974, p. 297).

\footnotetext{
39 Zelený atribuía uma importância central a estes estudos no interior da conjuntura teórica sucessiva a morte de Stalin: "Recolocar a questão da lógica de $O$ Capital (...) permite, na minha opinião, elaborar também alguns critérios uteis para a discussão com as tendências do pensamento marxista presente que na sua crítica do dogmatismo se manteve na cisão entre a intenção antropológica e cientificista". (Zelený, 1974, p. 12)

${ }^{40} \mathrm{Ou}$ ainda em outra passagem, referindo-se ao significado da ontopraxeologia afirma: "fundamentos do saber, da prática humana e da natureza". (Zelený, 1974, p. 325). A ontopraxeologia refere-se, portanto, as esferas do ser, da prática e da razão.
}

\begin{tabular}{|l|l|l|l|l|}
\hline Qevista Dialectus & Ano 3 & n. 8 & Janeiro - Agosto 2016 & p. 116-133 \\
\hline
\end{tabular}




\section{SOBRE ALGUMAS TENTATIVAS DE SUPERACÃO DO DOGMATISMO...}

Pedro Leão da Costa Neto

\section{Conclusão}

Sem ter por objetivo uma investigação exaustiva da produção teórica do marxismo tcheco nos 1960 ou uma minuciosa exegese dos textos de três de seus destacados representantes - Zelený, Kosik e Kalivoda - os objetivos centrais desta comunicação foram ressaltar, através da análise de uma conjuntura teórica determinada, em primeiro lugar, o caráter arbitrário da utilização, de forma acrítica e generalizada de conceitos generalizantes como de "marxismo soviético", "marxismo oriental" e "marxismo ocidental"; em segundo lugar, procurou-se sublinhar a necessidade de uma reconstrução histórica de uma conjuntura teórica específica, a partir dos seus diferentes aspectos constitutivos. Esta reconstrução permitiu ressaltar algumas particularidades dos diferentes projetos teóricos que foram criados como distintas estratégias para sair da crise do dogmatismo que tinha se instalado no marxismo desde o início dos anos 1930.

\section{Referências}

ARNASON, J. P. Perspectivas e problemas do marxismo critico no Leste europeu. In: HOBSBAWM, E. J. História do Marxismo Vol. XI. Rio de Janeiro: Paz e Terra, 1989.

CLAUDÍN, F. A oposição no 'socialismo real” União Soviética, Hungria, Polônia, Tchecoslováquia 1953/1980. Rio de Janeiro: Marco Zero, 1983.

COLE, G. D. H. Historia del Pensamiento Socialista Vol. V Comunismo y Socialdemocracia 1914-1931 (Primera Parte). 4ª reimpr., México: FCE, 1986.

COLE, G. D. H. Historia del Pensamiento Socialista. Vol. VII Socialismo y Fascismo 1931-1939. 2a reimpr., México: FCE, 1975.

FEJTÖ, F. Histoire des démocraties populares. Tome I. L’ère de Staline. Paris: Seuil, 1972a.

FEJTÖ, F. Histoire des démocraties populares. Tome II. Après Staline. Paris: Seuil,1972b.

HÁJEK, M. Historia de la Tercera Internacional. Barcelona: Crítica, 1984.

HRZAL, L. Sugli attuali compiti dela filosofia e dela sociologia nella Repubblica Socialista Cecoslovacca. In: Aut-Aut. Milano, n. 140, 1974.

HUSSERL, E. A Crise das Ciências Européias e a Fenomenologia Transcendental Uma Introdução à Filosofia Fenomenológica. Rio de Janeiro: Forense Universitária, 2012.

\begin{tabular}{|l|l|l|l|l|}
\hline Revista 2 ialectus & Ano 3 & n. 8 & Janeiro - Agosto 2016 & p. 116-133 \\
\hline
\end{tabular}


KALIVODA, R. La realtà spiritual moderna e il marxismo. Torino: Einaudi, 1971. KOŁAKOWSKI, L. Główne Nurty Marksizmu, Vol. III: Rozkład. Varsóvia: Krąg Pokolenie, 1988.

KONRAD, K. La disputa su contenuto e forma. Osservazioni marxiste sul nuovo formalismo. In. GÜNTHER, H. (Org.) Marxismo e Formalismo Documenti di una controversia teorico-letteraria. Napoli: Guida, 1975.

KOSIK, K. La Nostra Crise Attuale. Roma: Riuniti, 1969.

KOSIK, K. Dialética do Concreto. 1. Reedição, Rio de Janeiro: Paz e Terra, 1976.

KOSIK, K. La Crise des Temps Modernes: Dialectique de la Morale. Paris: Les Éditions de la Passion, 2003.

KOSIK, K. Un filosofo in tempi di farsa e di tragedia Saggi di pensiero critico 19642000. Milano: Mimesis, 2013.

KOUŘÍM, Z. La Dialectica en Cuestion. Buenos Aires: Paidos, 1974.

KOZYR-KOWALSKI, S. Socjologia, Spoleczeństwo obywatelskie i Państwo. Poznań: Wydawnictwo Naukowe UAM, 2004.

KRAJEWSKI, W. Introduction: Polish Philosophy of Sciences. In: KRAJEWSKI, W (Org.). Polish essays in the philosophy of the Natural Sciences. Dordrecht: D. Reidel, 1966.

KRIEGEL, A. Las Internacionales Obreras. Barcelona: Martinez Roca, 1968.

LIEHM, A. Entretien avec Karel Kosik. In: LIEHM, A. Trois generations Entretiens sur le phénomène culturel tchécoslovaque. Paris: Gallimard, 1970.

LIEHM, A. Le Passé Present Le socialisme oriental face au monde moderne. Paris: JCLattès, 1974.

MÁRKUS, G. Teoria do Conhecimento no Jovem Marx. Rio de Janeiro: Paz e Terra, 1974.

MARX, K. O Capital: Critica da Economia Política, Livro III, Tomo 2, São Paulo: Abril Cultural, 1983.

MARX, K.; ENGELS, F. A Ideologia Alemã. Rio de Janeiro: Civilização Brasileira, 2007.

MATĚJKA, O. Entre les sciences sociales et la construction de la "société socialiste". In: Cahiers du CEFRES, 2012.

MATHESIUS, V. Les Thèses de 1929. In: Le Cercle de Prague. Paris: Seuil, 1969.

MEJBAUM, W.; ZUKROWSKA, A. Literat Cywilizowanego Swiata. Leszek

\begin{tabular}{|l|l|l|l|l|}
\hline Rovista Qialectus & Ano 3 & n. 8 & Janeiro - Agosto 2016 & p. 116-133
\end{tabular}


Kolakowski a krysys mysli mieszczanskiej. Varsóvia: Ksiazka i Wiedza, 1985.

MLYNÁŘ, Z. Mróz ze Wschodu. Varsóvia: Nowa, 1988.

MUKǍ̆OVSKÝ, J. Formalisme russe, Structuralisme tcheque Réponse de Mukařovský. In: Le Cercle de Prague. Paris: Seuil, 1969.

MUKǍ̌OVSKÝ, J. Entretien avec Jan Mukařovský. In: Le Cercle de Prague. Paris: Seuil, 1969.

MUKAŘOVSKÝ, J. Sobre o estruturalismo. In: MUKAŘOVSKÝ, J. Escritos sobre Estética e Semiótica da Arte. Lisboa: Estampa, 1988, p.135-148.

PAGANINI, G. La filosofia negli altri paesi europei. In. DAL PRA, M. Storia della filosofia, Vol. X. La filosofia contemporanea: il Novecento. Milano: Vallardi,1978.

RAINKO, S. Kilka tez o sytuacji marksizmu. In: RAINKO, S. Swiadomosc i Krytyka. Varsóvia: Czytelnik. 1989.

REZEK, P. La “phénoménologie de l'esprit" de Patocka dans le context du Cercle philosophique de Prague. In: Les Cahiers de Philosophie. Jan Patočka le soin de l'âme. Lille, n.11/12, 1990/1991.

SCHAFF, A. Filozofia Czlowieka, Varsóvia: K i W, 1965.

ŚPIEWAK, P. Żydokomuna Interpretacja historyczne. Varsóvia: Czerwone i Czarne, 2012.

TOMASZEWSKI, J. Czechosłowacka Republika Socjalistyczna. In. Dzieje Państwa Socjalistycznych Gospodarka, Społeczeństwa Polityka. Varsóvia: PWE, 1987.

TOMASZEWSKI, J. Europa Środkowo-Wschodnia 1944-1968 Powstanie, Ewolucja i Kryzys realnego socjalizmu. $2^{\mathrm{a}}$ ed. Vársóvia: Wydawnictwa Uniwersytetu Warszawskiego, 1992.

ZANARDO, A. La ricerca filosofica marxista e il problema degli intellettuali nei paesi socialisti. In: Critica Marxista. Roma, 1963, n. 3.

ZANARDO, A. La Filosofia marxista in Cecoslovacchia negli anni 1945-1960. In: ZANARDO, A. Filosofia e Socialismo. Roma: Riuniti, 1974.

ZELENÝ, J. La Estructura Lógica de 'El Capital' de Marx. Barcelona: Grijalbo, 1974.

ZELENÝ, J. Dialéctica y Conocimiento. Madri: Cátedra, 1982.

ZUMR, J. O Filozofii czeskiej. In: Argumenty. Ano VII. Varsóvia, 9.06.1963a.

ZUMR, J. Świat i Czlowiek. In: Zeszyty Argumentów. Varsóvia, 5/10-6/11. 1963b.

\begin{tabular}{|c|c|c|c|}
\hline Gonista Dialectus & Ano 3 & n. 8 & Janeiro - Agosto 2016 \\
\hline
\end{tabular}

